(6)

\section{OPEN ACCESS}

For numbered affiliations see end of article.

Correspondence to Dr Wasim Maziak, Department of Epidemiology, Robert Stempel College of Public Health and Social Work, Florida International University, Syrian Center for Tobacco Studies, 11200 SW 8TH ST, Miami, FL 33199, USA; wmaziak@fiu.edu

Received 13 August 2014 Accepted 8 September 2014 Published Online First 8 October 2014

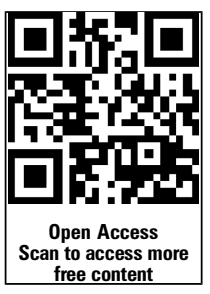

CrossMark

To cite: Maziak W, Taleb ZB, Bahelah R, et al. Tob Control 2015;24:i3-i12.

\title{
The global epidemiology of waterpipe smoking
}

\author{
Wasim Maziak, ${ }^{1,2}$ Ziyad Ben Taleb, ${ }^{1}$ Raed Bahelah, ${ }^{1,3}$ Farahnaz Islam, ${ }^{4}$ Rana Jaber, ${ }^{1}$ \\ Rehab Auf, ${ }_{1}^{1}$ Ramzi G Salloum ${ }^{5}$
}

\begin{abstract}
Objectives In the past decade, waterpipe smoking (a.k.a. hookah, shisha, narghile) has become a global phenomenon. In this review, we provide an updated picture of the main epidemiological trends in waterpipe smoking globally.
\end{abstract}

Data sources Peer-reviewed publications indexed in major biomedical databases between 2004 and 2014. Search keywords included a combination of: waterpipe, hookah, shisha along with epidemiology, patterns, prevalence and predictors. We also used different spellings of waterpipe terms commonly used.

Study selection The focus was on studies with large representative samples, national data or high-quality reports that illuminated aspects of the epidemiology and trends in waterpipe smoking.

Data extraction Multiple researchers extracted the data independently and collectively decided on the most important and pertinent studies to include in the review. Data synthesis Waterpipe smoking has become a global phenomenon among youth. The global waterpipe epidemic is likely driven by (1) the introduction of manufactured flavoured tobacco (Maassel); (2) the intersection between waterpipe's social dimension and thriving café culture; (3) the evolution of mass communication media; (4) the lack of regulatory/policy framework specific to the waterpipe. Waterpipe smoking is becoming the most popular tobacco use method among youth in the Middle East, and is quickly gaining popularity elsewhere. Important patterns of waterpipe smoking include the predominance among younger, male, high socioeconomic, and urban groups. Intermittent and social use are also noted patterns. Conclusions Waterpipe smoking has become a global public health problem. Developing surveillance, intervention and regulatory/policy frameworks specific to the waterpipe has become a public health priority.

\section{INTRODUCTION}

In 2004, we published in Tobacco Control the first comprehensive review on the waterpipe (also known as shisha, hookah, arghile and narghile) in response to what seemed to be an emerging epidemic, particularly in the Middle East. ${ }^{1}$ A decade later, the global evolution of this smoking habit has exceeded worst predictions. Epidemiological data from countries that performed surveillance of waterpipe use have captured alarming trends. In the Middle East, the waterpipe has quickly replaced cigarettes as the most popular method of tobacco use among youth, and in several other parts of the world, it is becoming second only to cigarettes. ${ }^{2}$

In its most common form nowadays, the waterpipe involves the passage of charcoal-heated air through a perforated aluminium foil and across the flavoured tobacco (a.k.a. Maassel) to become smoke that bubbles through the water before inhalation by the smoker (figure 1). Available evidence shows that waterpipe smoking is harmful, addictive, can provide a gateway to cigarettes, as well as thwart cessation efforts. ${ }^{3}$ Prior to the 1990 s, this tobacco use habit germane to the Middle Eastern region was becoming less practiced, and gradually confined to older men. This is based on observations mostly, since quality epidemiological estimates of the spread of waterpipe smoking in the Middle East were scarce before the 1990s. This could be partly due to weakness of smoking surveillance across the region, but perhaps suggestive of limited spread as well. ${ }^{14}$ The epidemiological landscape of waterpipe smoking started to change in the early 1990s, when waterpipe smoking began spreading among youth, first in the Middle East and soon after in other parts of the world. ${ }^{156}$

\section{METHODS}

For this thematic review we searched peer-reviewed publications indexed in major biomedical databases including PubMed, CINAHL, PsychInfo and Cochrane Library, between 2004 and 2014, as well as databases of global tobacco use surveillance systems such as the Global Youth Tobacco Survey (GYTS). Keywords included a combination of: waterpipe, hookah, shisha, epidemiology, patterns, prevalence and predictors. We also used different spellings of waterpipe terms commonly used (eg, narghile, arghile, narguila). As the focus of this review is on drawing an updated picture of the main epidemiological trends in waterpipe smoking globally, priority was given to studies with large representative samples, national/international data or high-quality reports that illuminated aspects of the epidemiology and trends in waterpipe smoking. Multiple researchers extracted the data independently and collectively decided on most important and pertinent studies to include in the review. Our aim is not to include all relevant articles to the review's theme, but to showcase main trends and provide some of high-quality studies and data to illustrate these trends.

\section{RESULTS AND DISCUSSION}

In this review we will start with discussing the main factors contributing to the spread of waterpipe globally, and discuss its main epidemiological trends and use pattern. Such knowledge is important to understand the dynamics and anatomy of the global waterpipe epidemic, and to guide a proportionate and informed response to its spread. 


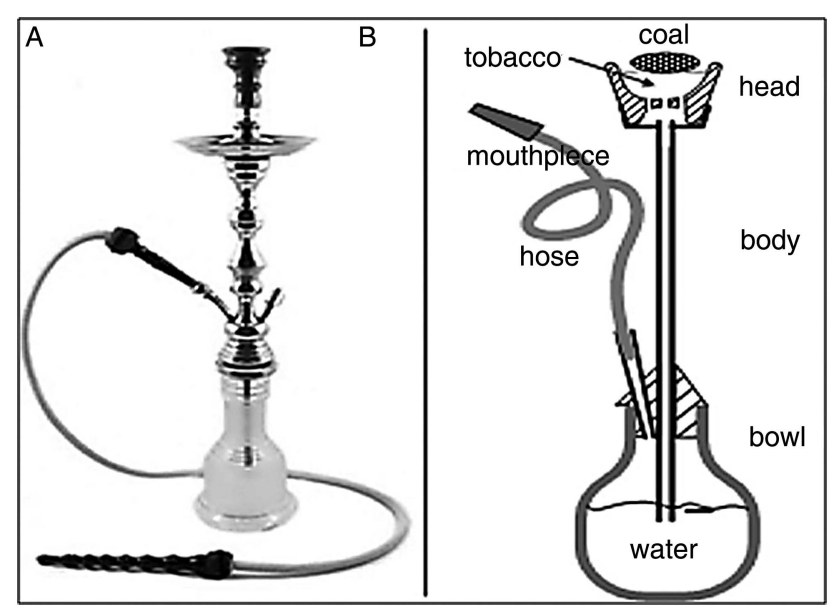

Figure 1 (A) Waterpipe device, (B) with presentation of its main parts.

\section{Factors contributing to the global emergence of waterpipe smoking}

As with many complex behavioural trends, it is hard to pin down factors responsible for the global spread of waterpipe smoking. Most likely, a combination of influences and developments within and outside the context of the behaviour collide to result its popularity. In such circumstances, a less conventional analysis of converging lines of evidence from different sources can help explain the likely drivers behind the global spread of waterpipe smoking. Here, we single out four such factors.

1. The introduction of flavoured waterpipe tobacco (a.k.a. Maassel): It is difficult to trace the first production of sweetened and flavoured waterpipe tobacco commonly called Maassel, but it was already in use in the early 1990s. ${ }^{7}$ Maassel is typically manufactured through the fermentation of tobacco with molasses, glycerine and fruit essence producing a moist and pliable mixture. Prior to the introduction of Maassel, most waterpipe smokers used some form of raw tobacco that they manipulated (eg, crushed, mixed with water, squeezed and moulded) prior to use. This method usually produces strong and harsh smoke, unlike the smooth and aromatic smoke produced with Maassel. ${ }^{7}$ In retrospect, the introduction of Maassel for waterpipe was equivalent to the invention of the Bonsack machine that allowed mass production and marketing of cigarettes. What Maassel did was to industrialise and commercialise the product; increase its availability and variety; make it appealing to youth through flavour variety; pave the way for mass marketing through the Internet; and simplify the waterpipe preparation process. ${ }^{8}$

Data from all over the world show that Maassel is the preferred tobacco used with waterpipe for the majority of smokers, especially youth. For example, in a survey conducted in 2010 involving 3447 students from eight colleges in North Carolina (US), $90 \%$ of ever waterpipe smokers use it with flavoured tobacco. ${ }^{9}$ Many waterpipe smokers furthermore, were drawn to this tobacco use method because of Maassel's aromatic and smooth smoke as well as variety of flavours. ${ }^{10}$ Finally, anecdotal evidence from the Middle East suggests a temporal link between the production of Maassel at the beginning of the 1990 s and the surge in the number of waterpipe smokers. ${ }^{5}$

2. The intersection between the social nature of waterpipe smoking and café culture: The strong social dimension of waterpipe smoking is well characterised. ${ }^{16-10}$ Many waterpipe smokers practice the habit in the company of friends and family, and treat it as a central element of social and family gatherings. ${ }^{711} 12$ Sharing the same waterpipe is also a well-recognised and widespread practice, especially among youth. ${ }^{13}$ The long sessions (averaging an hour) and slow pace of waterpipe smoking moreover, make the waterpipe an optimal object for social interactions, especially in café settings. And when a boom in the café culture in the Middle East and beyond took place, ${ }^{10}$ the waterpipe was a natural fit.

One of the milestone developments in this regard was the introduction of Ramadan tents in the Middle East during the 1990s. These were a special form of cafés that hosted social gatherings during the Muslim holy month of Ramadan. People, especially youth, go there in the evening (after breaking their fast) and the waterpipe was the centrepiece for such setting. ${ }^{14}$ It provided the nicotine for smokers who could not smoke during fasting hours, the social experience that is especially lively during Ramadan, and the lengthy sensory indulgence after the strict deprivation of fasting. Soon these tents were the subject of television programmes and entertainment activities that were transmitted through satellite media all over the Middle East. ${ }^{14}$

As the new trend gained appeal among tourists and youth outside of the Middle East, Middle Eastern expatriates around the world ventured the opening of waterpipe cafés and restaurants as a promising commercial enterprises. From thereafter, the idea took a life of its own, and such venues started mushrooming in most urban centres around the world, mostly benefiting from the weak or absent regulatory environment for the waterpipe. In the UK for example, there are currently about 400 waterpipe cafes in London alone, and in the US, hookah cafés have increased dramatically in the past decade especially around college campuses. ${ }^{13}{ }^{15}$ Such logistically situated venues can encourage waterpipe smoking, as shown in a study of $3770 \mathrm{stu}-$ dents from eight American universities, where waterpipe smoking was associated with the presence of waterpipe venues within a 10-mile radius from university campus. ${ }^{16}$

3. The Internet, mass and social media: A local trend will likely remain local or spread very slowly in the absence of systems of global communication and mass media. The waterpipe epidemic in particular, was a beneficiary of two such developments. The first happened in the 1990s with the explosion of unregulated, inexpensive and widely accessible satellite television throughout the Middle East. New channels were being launched regularly with airtime to be filled, while cheap satellite television quickly became the main entertainment medium for the masses. As a result, featured programmes with social activities involving the waterpipe were soon widely disseminated throughout the region (eg, programmes from Ramadan tents). ${ }^{14}$

The other technological innovation behind the increasing popularity of waterpipe smoking among the educated youth was the Internet. As the popularity of waterpipe use among youth became established, waterpipe businesses soon realised how the Internet can be used to market the product to them. This was particularly relevant to the spread of waterpipe outside of the Middle East, where waterpipe cafés are more sparsely located. Our team has recently conducted an analysis of trends in search engine queries related to the waterpipe, and compared them with similar trends for electronic cigarettes between 2004 and 2013 in four western countries (Australia, Canada, the UK and the USA). ${ }^{17}$ We found that Internet-based searches for waterpipe have increased steadily since 2004 in all four countries, and were higher for waterpipe than e-cigarettes in three countries, with the highest search volume found in the US (figure 2). ${ }^{17}$ 
Online searches were primarily targeted at waterpipe products for home use, followed by searches for waterpipe cafés and lounges. ${ }^{17}$

The largely unregulated Internet allowed waterpipe promoters to circumvent most of the advertisement bans and reach their preferred customers pool through this means. In an analysis of 144 websites of waterpipe venues in the US, only 4\% were found to include tobacco-related health warnings on their pages. ${ }^{18} \mathrm{~A}$ related analysis of cigarette-related and waterpipe-related YouTube videos found that user-generated videos of the waterpipe were less likely to acknowledge the negative health consequences of smoking compared to cigarette videos; $92 \%$ of waterpipe-related videos portrayed smoking in a positive light compared to only $24 \%$ of cigarette-related videos. ${ }^{19}$ Much of that promotion on the internet and social media is organised around Interest groups, but in fact disguise waterpipe sellers and marketers ${ }^{18-20}$ (see eg, http://www.hookahblogger.tumblr.com/ and http://www.hookah-shisha.com/hookahlove/).

4. Lack of waterpipe-specific policies and regulations: Despite the remarkable success of public health policy in reducing cigarette smoking in many countries, waterpipe smoking has thrived in the wake of strict tobacco control policies and regulations that were mostly tailored for cigarettes. Waterpipe venues and products in many developed countries are exempt from tobacco control policies, while the additional lack of enforcement of existing policies in developing
Figure 2 Internet search patterns for waterpipe and e-cigarettes in four countries (US, UK, Canada and Australia). ${ }^{17}$
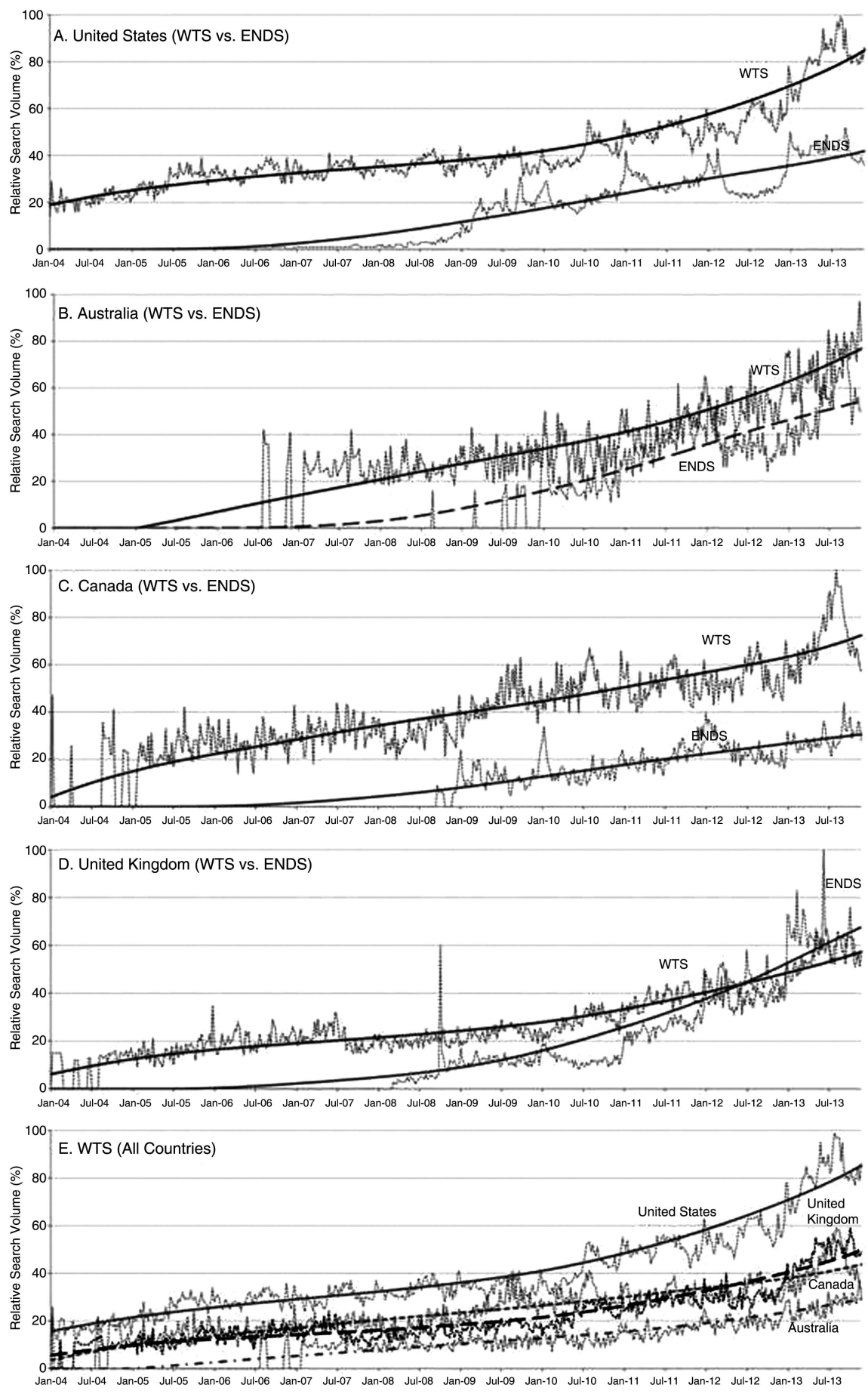
countries have contributed to the proliferation of these venues. ${ }^{6}{ }^{21}$ For example, bans on flavouring, considered to be a major factor in the appeal to youth, often exclude waterpipe flavoured tobacco. ${ }^{22}$ Moreover, while cigarette pack size and packaging are somewhat uniform across the world, and while the cigarette tobacco industry is well defined and concentrated, this is not the case for the waterpipe. Compared with cigarettes, the waterpipe varies in shape and size, is less portable and comprised of multiple parts, is often shared, and has diverse financial stakeholders. These characteristics imply that many policy-related elements need to be waterpipe-specific. ${ }^{23}$ So for health warnings for example, individual consumers may not see the tobacco package if they are served the waterpipe in a café, and smokers are potentially exposed to health risks beyond those directly attributable to tobacco (eg, charcoal combustion, spread of infections from sharing and repeated use). ${ }^{7} 2425$ More so, whereas most price-based policies have been shown to be effective in curtailing the demand for cigarettes, ${ }^{26}{ }^{27}$ raising the price of waterpipe Maassel may not have the same effect across the board. For example, in a café/restaurant setting in the Middle East, tobacco usually constitutes a small component of the profit margin compared to food and beverages. ${ }^{6}$ And since anyone can prepare homemade Maassel from relatively cheap ingredients, ${ }^{28}$ waterpipe smokers may be less price-sensitive than cigarette smokers.

The issue of policy and regulation as it pertains to the waterpipe is discussed in detail in this supplement (see Jawad et al). In summary, in the absence of adequate regulatory framework, several societal and technological developments have allowed the social tobacco use method of waterpipe spread globally. $^{6} 182930$

\section{The epidemiology of waterpipe tobacco smoking}

Global spread

Given the relative novelty of the waterpipe epidemic, few countries have conducted regular surveillance of waterpipe smoking. ${ }^{31}$ In countries where national or representative data about waterpipe use are collected, the trends are quite alarming. ${ }^{31}$ In the Middle East particularly, several epidemiological surveys have documented the dramatic popularity of waterpipe smoking among youth, ${ }^{31} 32$ showing that it has already replaced cigarettes as the most common form of tobacco use (figure 3). For example, a multicountry study involving representative samples of 13-15-year-old school children in several countries in the Arabian Peninsula (Bahrain, Oman, Qatar, United Arab Emirates, Kuwait and Yemen) showed a prevalence of waterpipe smoking ranging from $9 \%$ to $15 \%$, and mostly surpassing the prevalence of cigarette smoking. ${ }^{33}$

Recent evidence from dispersed populations around the world shows that the rest of the world is catching up with the waterpipe trend. ${ }^{34}$ For example, according to a recent survey involving more than 100000 students from 152 colleges and universities in the US, current waterpipe smoking was reported by $8.4 \%$ of students, second only to cigarettes. ${ }^{35}$ Two recent studies have documented for the first time higher use prevalence for waterpipe compared to cigarettes in samples of youth from Western societies. The first was conducted among a sample of students ( $\mathrm{N}=2399 ; 50 \%$ male; mean age 14.5 years) from 15 secondary schools in Brent (northwest London, UK), and showed that current waterpipe smoking prevalence was more than double of cigarette smoking $(7.6 \%$ vs $3.4 \%),{ }^{36}$ and the second was conducted on the campus of the University of Florida (USA) with 1203 participants (mean age $\approx 21.5$ years; $45.7 \%$ males), where waterpipe smoking significantly exceeded cigarette smoking for both ever use $(46.4 \%$ vs $42.1 \%)$ and past year use $(28.4 \%$ vs $19.6 \%){ }^{37}$

Data from other parts of the world are painting a similar picture. For example, in a 2006 national survey of Estonian students ( $N=13$ 826; age 11-15 years), waterpipe use was reported by $25 \%$ of boys and $16 \%$ of girls. ${ }^{38}$ The most recent data from the National Youth Tobacco Survey (NYTS; 2012) in the USA involving 24658 participants (6-12th graders) show that current waterpipe smoking occupied the third place in terms of spread among 6-12 graders, and the fourth place for spread among high school students (5.4\%) behind cigarettes (14\%), cigars $(12.6 \%)$, smokeless tobacco $(6.4 \%)$ and ahead of ecigarettes (2.8\%). ${ }^{39}$ In Canada, a recent analysis of the 2010 Canadian Youth Smoking Survey data from students in grades 9-12 $(\mathrm{N}=31$ 396) shows that the prevalence of ever waterpipe use among those students was $10 \% .{ }^{40}$ The available evidence from Australia comes from a telephone survey conducted in 2004 and involved 1102 Arabic-speaking adults in southwest Sydney, where current waterpipe smoking was reported by $11.4 \%$ of participants. ${ }^{41}$

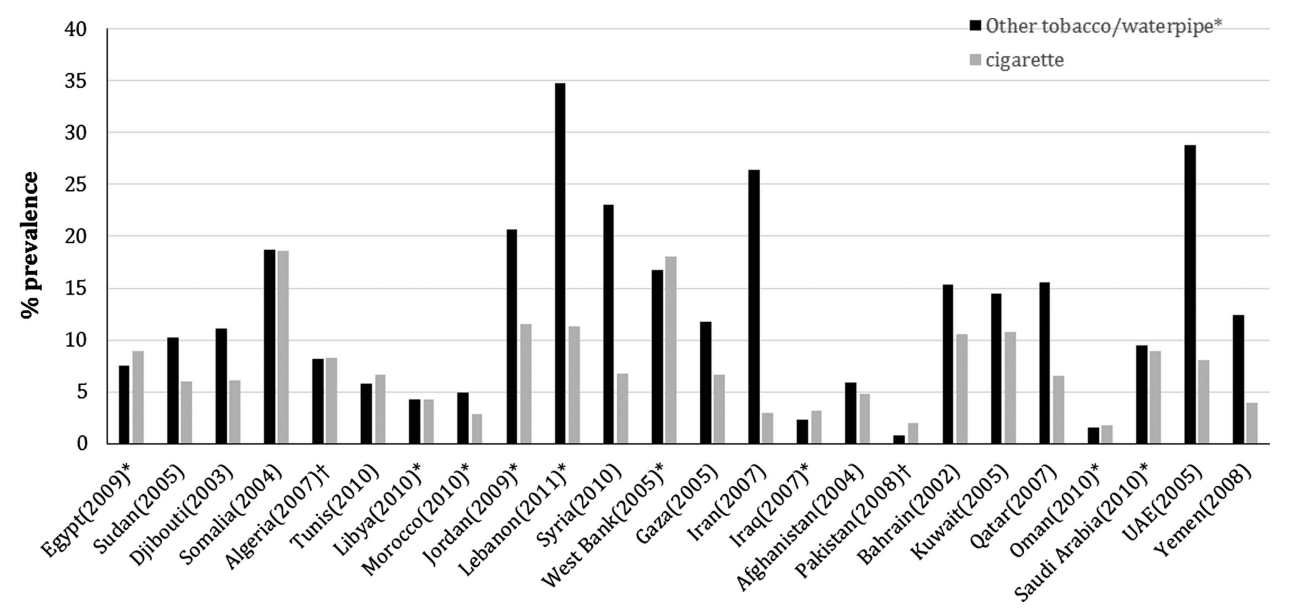

Figure 3 Current other tobacco/waterpipe vs cigarette smoking among adolescents 13-15 year-olds in selected countries according to the most recent Global Youth Tobacco Survey (GYTS). ${ }^{42}$ * Specifically inquired about waterpipe smoking, otherwise it is represented by other tobacco use (mostly waterpipe in the Eastern Mediterranean region). ${ }^{32} 4344$ tMore than one survey, and the average of their prevalence measures is reported. 


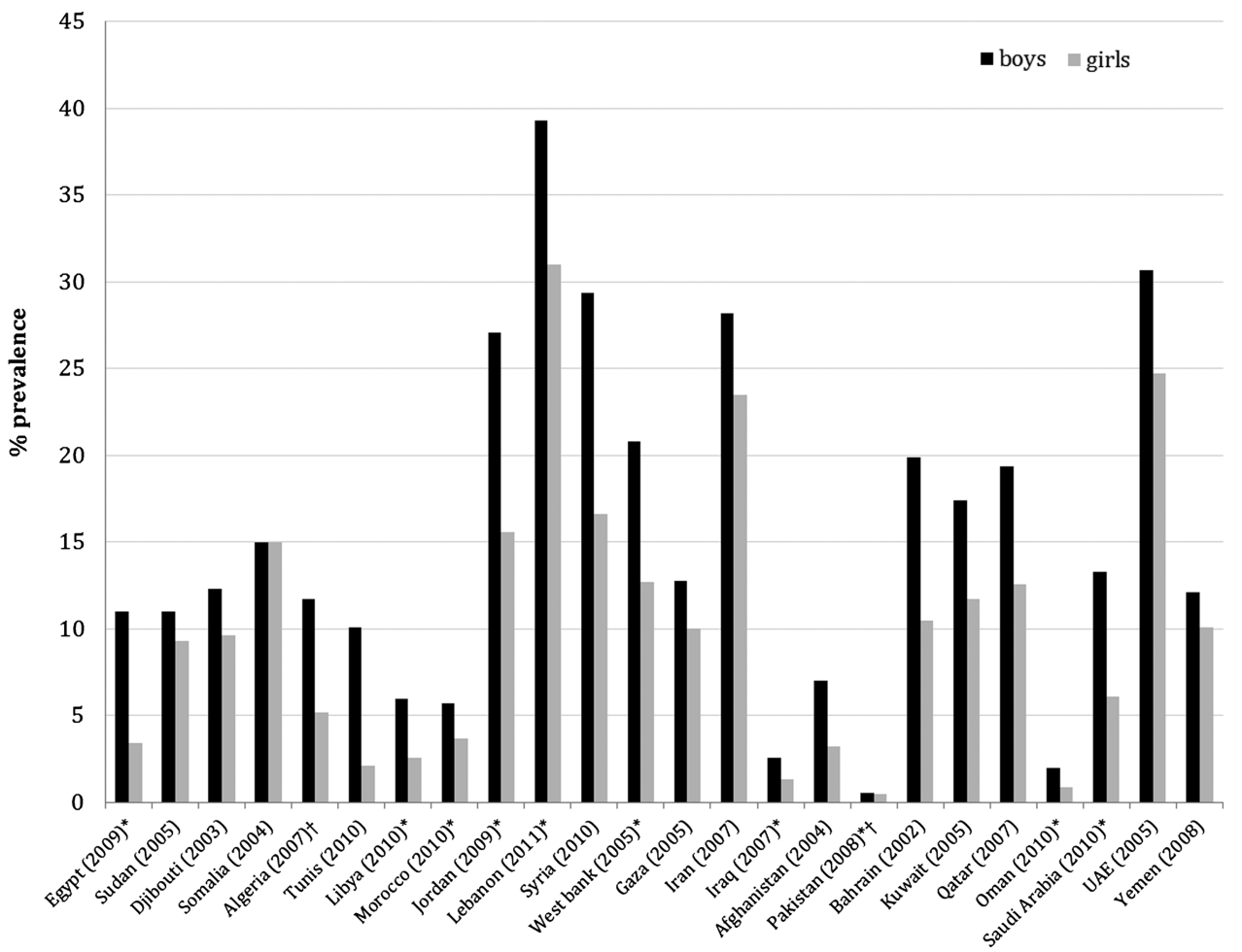

Figure 4 Gender-specific prevalence of current other tobacco/waterpipe smoking among adolescents (13-15 years-old) in selected countries according to the most recent Global Youth Tobacco Survey (GYTS). ${ }^{42}{ }^{*}$ Specifically inquired about waterpipe smoking, otherwise it is represented by other tobacco use (mostly waterpipe in the Eastern Mediterranean region)..$^{32} 4344$ tMore than one survey, and the average of their prevalence measures is reported.

One of the main challenges in trying to capture a broad epidemiological snapshot of a risk behaviour lies in comparing results from studies applying different methods and definitions. To overcome this obstacle, some initiatives have been introduced in the past decade to standardise tobacco use surveillance globally leading to the Global Tobacco Surveillance System. ${ }^{42}$ An essential component of this initiative is the GYTS; the largest to date surveillance of tobacco use among youth (13-15 years) with more than 200 surveys conducted in about 100 countries. Data from the GYTS from the Eastern Mediterranean region (EMR) and elsewhere indicate the predominance of waterpipe smoking among Arab youth (figures 3 and 4), ${ }^{42}$ and its global reach in this age group. ${ }^{34}$ For boys in the EMR, the GYTS reports the highest level of 'other tobacco use' (12\%), and lowest level of cigarette smoking (7\%) compared to other regions. ${ }^{43}$ Smoking among girls in the EMR according to the same source has the lowest level for cigarettes (2\%) compared to other regions, but the second highest for 'other tobacco use' (9\%). Such dramatic differences were attributed to waterpipe smoking. ${ }^{32} 4344$ The other component of GTSS, the Global Adult Tobacco Survey (GATS) of persons aged $\geq 15$ years from different countries around the globe shows the spreading popularity of waterpipe smoking even among adult populations (age $15+$ years; figure 5$).{ }^{45}$

\section{Time trends}

As with prevalence data, it is difficult to construct a clear picture of the time evolution of a risk behaviour, when different definitions, methods, and samples are employed in different populations. However, few standardised surveillance efforts have been performed in recent years that can help shed light on the temporal dynamics of the waterpipe epidemic globally. For example, 2 year (2011-2012) data from the NYTS in the US involving 43524 participants show a 32\% increase (from $4.1 \%$ to 5.4\%) in current waterpipe smoking between 2011 and 2012 among high school students, at a time when cigarette smoking was declining (figure 6). ${ }^{39}$ Data cited previously from the Canadian Youth Smoking Survey show a 6.3\% increase in ever waterpipe smokers among 9-12 graders between 2006 and $2010 .^{40}$ Furthermore, cohort data from school students in Jordan involving 1781 students (mean age at baseline 12.7 years; $50 \%$ boys) show that current waterpipe smoking among participants increased by $72 \%$ for boys and $136 \%$ for girls $\left(86 \%\right.$ overall) between 2008 and 2011. ${ }^{46}$ Finally, time trends from the GYTS (1999-2008) with more than half a million participants worldwide concluded that while cigarette smoking is either stable or declining in many parts of the world, other forms of tobacco are showing a rising trend, most notably waterpipe smoking (34 out of 97 survey sites globally). ${ }^{44}$

\section{Patterns of waterpipe use}

Another aspect of trying to provide a comparative context for the epidemiology of waterpipe smoking is to contrast it to cigarette smoking. For this purpose, definitions for waterpipe use that are consistent with those used for cigarette smoking (eg, ever, current, daily) need to be used. Cautiously, we need to be mindful that at least in adults, we are comparing a mainly daily smoking habit (cigarette) with a mainly intermittent one (waterpipe), and that different levels of waterpipe smoking are not captured with definitions such as current smoking (smoking within the past 30 days). Therefore, for a mainly intermittent tobacco use method, relying mostly on an intermittent measure of smoking (eg, current smoking), can create a false impression of high spread compared to cigarettes. For example, a systematic 
Figure 5 Global prevalence of current waterpipe smoking among persons aged $\geq 15$ years. ${ }^{45}$

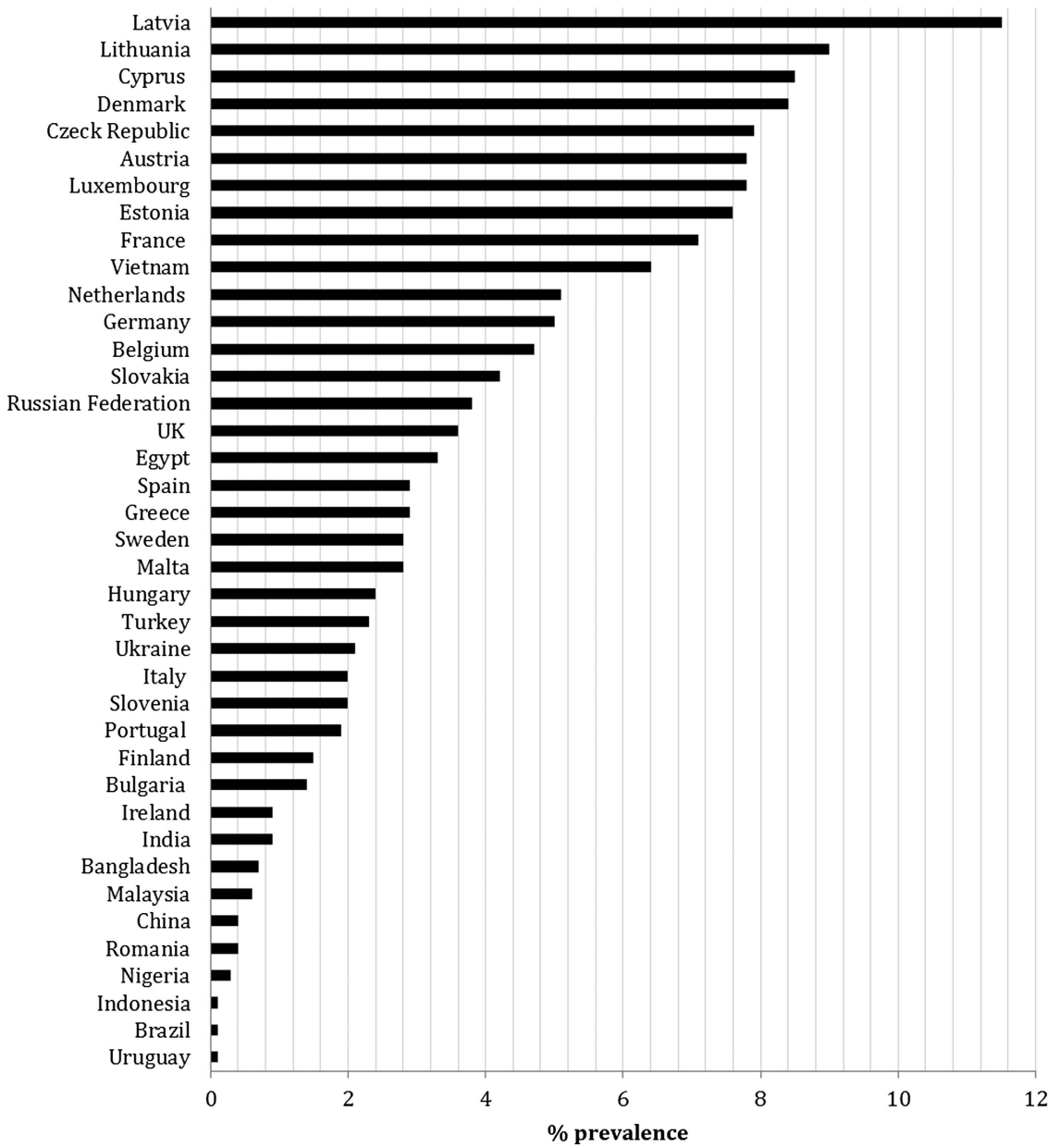

review of the studies looking at the epidemiology of waterpipe smoking globally, could not provide comparative maps of waterpipe use based on a single unified definition and the daily/intermittent differentiation was not entertained for the most part. ${ }^{31}$ What is not captured as well by using cigarette-based definitions is that the average time of waterpipe smoking cession is $1 \mathrm{~h}$ compared to 5 min for cigarettes, ${ }^{47}$ so information about time spent in smoking should be part of assessment of waterpipe use in population studies. Finally, some waterpipe smokers may not consider themselves as 'smokers' (the term mostly associated with cigarettes), ${ }^{48}$ so using waterpipe specific terms is imperative to capture the true spread of waterpipe smoking in epidemiological studies.

The daily/intermittent use paradox of waterpipe in comparison with cigarette is best demonstrated by data from a representative sample of adults aged 18-65 years in Aleppo (Syria). ${ }^{47}$ According to this study, most cigarette smokers were daily smokers, while most waterpipe smokers were intermittent smokers (figure 7). ${ }^{47}$ Data from other countries confirm this general pattern in adults. ${ }^{31}{ }^{49-52}$ For example, in a crosssectional study among 201 waterpipe smokers in the USA (80.1\% males, $85.6 \%$ aged $18-24$ years), 19\% reported daily use as compared with $41 \%$ weekly and $29 \%$ monthly use. ${ }^{51}$ In a qualitative study among 32 university students in London, 9 (28.1\%) students reported daily waterpipe smoking while 23 (71.9\%) reported weekly or less than weekly waterpipe smoking. ${ }^{52}$

With the expected variability in prevalence and patterns of use across regions and populations, waterpipe smoking generally presents some preponderance among male, young, and high socioeconomic groups. Figure 4 for example, demonstrates the gender difference in waterpipe smoking in the EMR, but similar gender-based trends have been registered in other parts of the world, as was captured by the NYTS data from the US (figure 6). Also noted among waterpipe users is a generally lower interest in quitting, and higher belief in ability to quit compared to cigarette smokers. ${ }^{53}$ 54 For example, data from 2012 NYTS show that $41.5 \%$ of current waterpipe smokers have the intention to quit compared to $56.8 \%$ of current cigarette smokers. ${ }^{55}$ Furthermore, being a habit closely linked to waterpipe cafés common in cities makes waterpipe smoking more of an urban phenomenon.

More consistent globally are the age-related trends in waterpipe use, with younger ages being the epicentre of the waterpipe epidemic. This waterpipe-age relationship can be best demonstrated in the aforementioned college and youth data from the USA, where waterpipe use peaks among 19-21 year olds compared to other age groups (figures 6, 8). ${ }^{35} 39$ Representative data from different countries around the world confirm the salience of waterpipe smoking among youth. ${ }^{7} 335156$ Contrary to the early days of waterpipe smoking (pre-1990), older people are now less likely to smoke the waterpipe compared to youth. For example, data from representative national samples of adults $\geq 40$ years from 10 countries in the Middle East $(\mathrm{N}=62086)$ show generally low prevalence of waterpipe smoking compared to cigarettes in this age group (figure 9 ). ${ }^{5}$

In terms of age of initiation, the picture is less clear, as would be expected from a tobacco use trend that is still evolving and 
Figure 6 Time trends of waterpipe (WP) and cigarette (Cig) ever smoking among youth in the USA: (A) for overall age groups, (B) girls and (C) Tobacco Survey, 2011-2012. ${ }^{39}$ boys according to the National Youth

A Overall cigarette (Cig) vs. waterpipe (WP) ever smoking by age groups, NYTS, 2011-2012

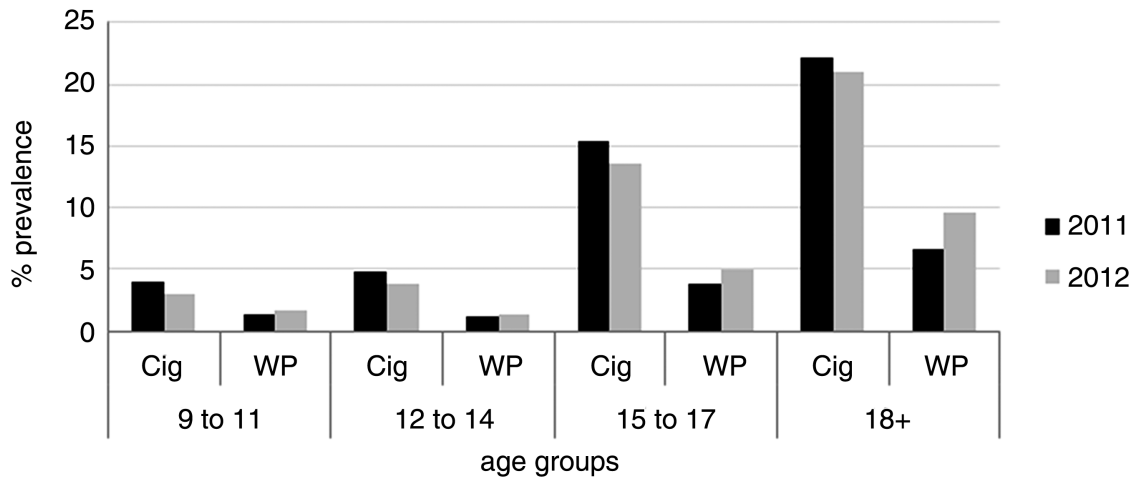

B Time trends cigarette (Cig) vs. waterpipe (WP) ever smoking among girls, NYTS, 2011-2012

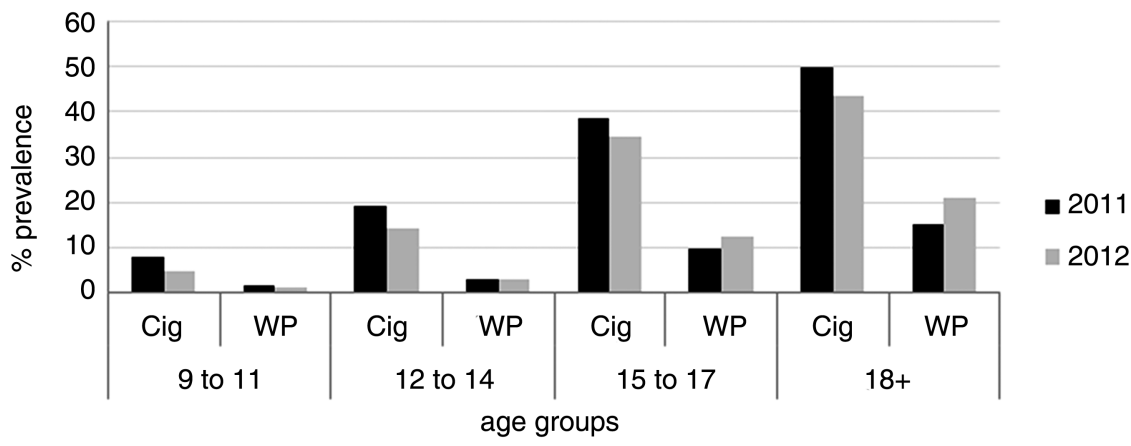

C Time trends cigarette (Cig) vs. waterpipe (WP) ever smoking among boys, NYTS, 2011-2012

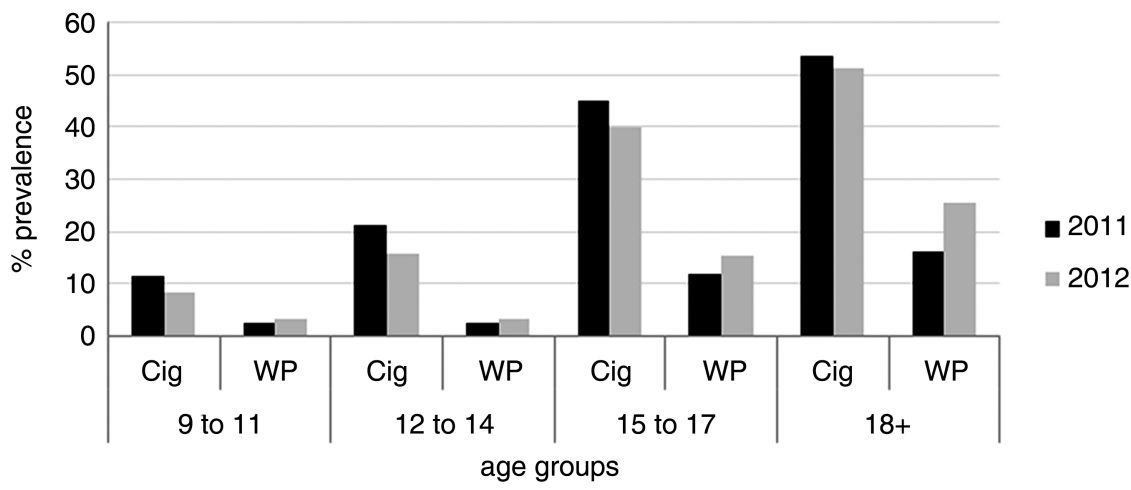

attracting new consumers of different ages. Compared to cigarettes, where most initiation usually takes place before the age of 18 years, ${ }^{58}$ the age of initiation for waterpipe smoking is much dependent on the age range of the sample studied. For example, in a study conducted in Syria comparing waterpipe smokers among university students (mean age 22 years) with older smokers in cafés (mean age 30 years), age of initiation of waterpipe use differed significantly between the two groups (20 vs 24 years), but was the same for cigarettes. ${ }^{55}$ Of note that in populations where waterpipe smoking is already an established culture, the age of initiation for waterpipe tends to be earlier than for cigarettes among youth. ${ }^{50} 59$

Other salient patterns of waterpipe smoking around the world include its association with higher socioeconomic status. For example, in a recent study involving 5540 high school seniors in the USA (years 2010-2012), 18\% of students reported waterpipe use in the past year. High parental education as well as students' income increased the odds of waterpipe use. ${ }^{60}$ Moreover, a recent online survey conducted in 20122013 among a representative sample of adults in Great Britain $(\mathrm{N}=24507 ; 88 \%$ aged $18+$ years) showed that those in the higher socioeconomic slice were twice as likely to be waterpipe smokers compared to those in the lower one. ${ }^{61}$ Our study among a representative sample of adults (18-65 years) in Aleppo, Syria alluded to earlier showed that waterpipe smoking prevalence is more than five times higher in adults with a favourable socioeconomic status compared to those with a less favourable one. ${ }^{47}$ Sharing the same waterpipe and smoking it in social groups are also common features of waterpipe smoking, although variable depending on the studied population and how 


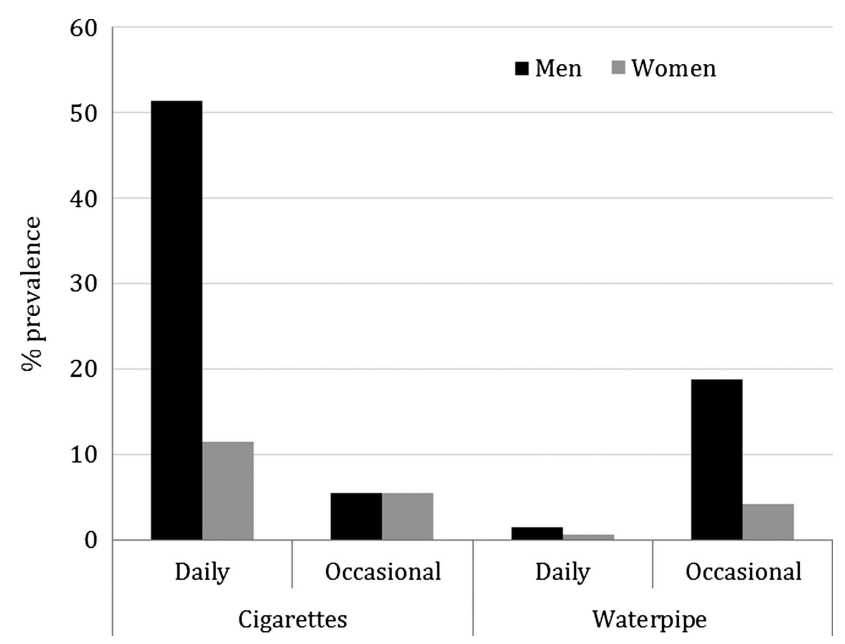

Figure 7 Waterpipe and cigarette smoking patterns among adults (18-65 years) in Syria. ${ }^{47}$

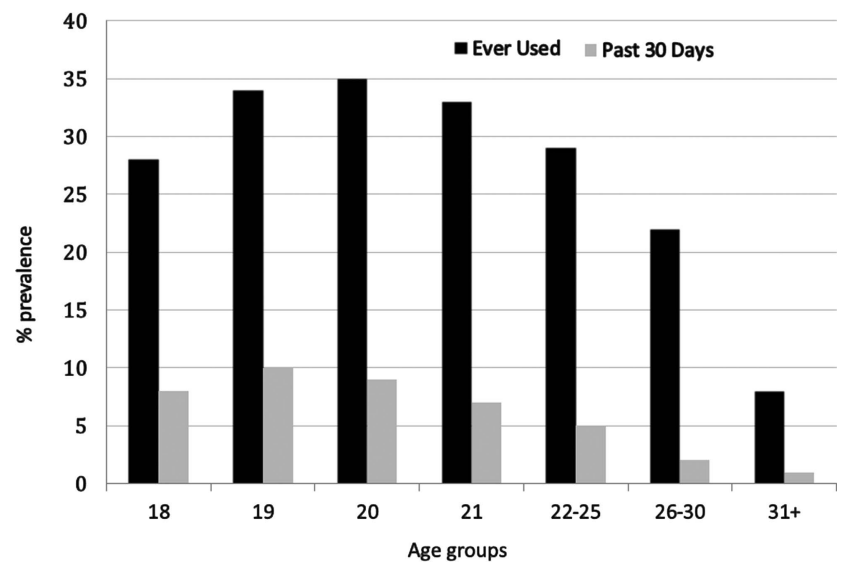

Figure 8 Age-related waterpipe use patterns among college students in the USA. ${ }^{35}$

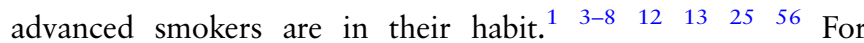
example, while $96.5 \%$ of beginning waterpipe smokers in Syria tend to share the same waterpipe with others, only $43.8 \%$ of established smokers do so. ${ }^{56}$

\section{Association with other behavioural risks}

The most identified associated behaviour for waterpipe smoking is cigarette smoking. Many studies from around the world have documented the salience of cigarette smoking among waterpipe smokers, and cigarette smoking has been shown to be a major predictor of waterpipe smoking among youth. ${ }^{46} 5962$ In the USA Monitoring the Future survey, waterpipe use among high school seniors was associated with current and former cigarettes smoking. ${ }^{58}$ Dual smoking however, tends to decrease with age, as older smokers are usually more loyal to a single tobacco use method. For example, in the study alluded to earlier comparing novice with established waterpipe smokers in Syria, ${ }^{56}$ the prevalence of dual smoking was $47.7 \%$ for novice smokers compared to $26.5 \%$ for established ones. These findings, coupled with recent evidence showing that waterpipe smoking can provide a gateway to cigarette smoking, ${ }^{63}$ suggests that smoking prevention efforts among youth need to address waterpipe smoking early on.

\section{CONCLUSIONS}

In epidemiological terms, trends in waterpipe smoking covering vast geographical territories, diverse populations, and encompassing several sectors of society are indicative of an epidemic rather than a passing fad. ${ }^{64}$ Many factors such as the Introduction of Maassel, the thriving café culture, the rise of the internet and social media and the lack of regulations have created optimal conditions for the spread of waterpipe smoking globally. Waterpipe smoking has become the most common method of tobacco use among youth in the Middle East and is steadily becoming a leading tobacco use method worldwide. As a risk behaviour, waterpipe smoking seems to cluster among younger age groups, males, the educated and those who smoke cigarettes. In several populations, waterpipe smoking is providing young people with their first tobacco experience and predisposing them to cigarette smoking. In the face of such a
Figure 9 Smoking behaviours among representative samples of individuals aged $\geq 40$ years (total 62086 ) in 10 countries in the Arab region, together with Pakistan. ${ }^{57}$

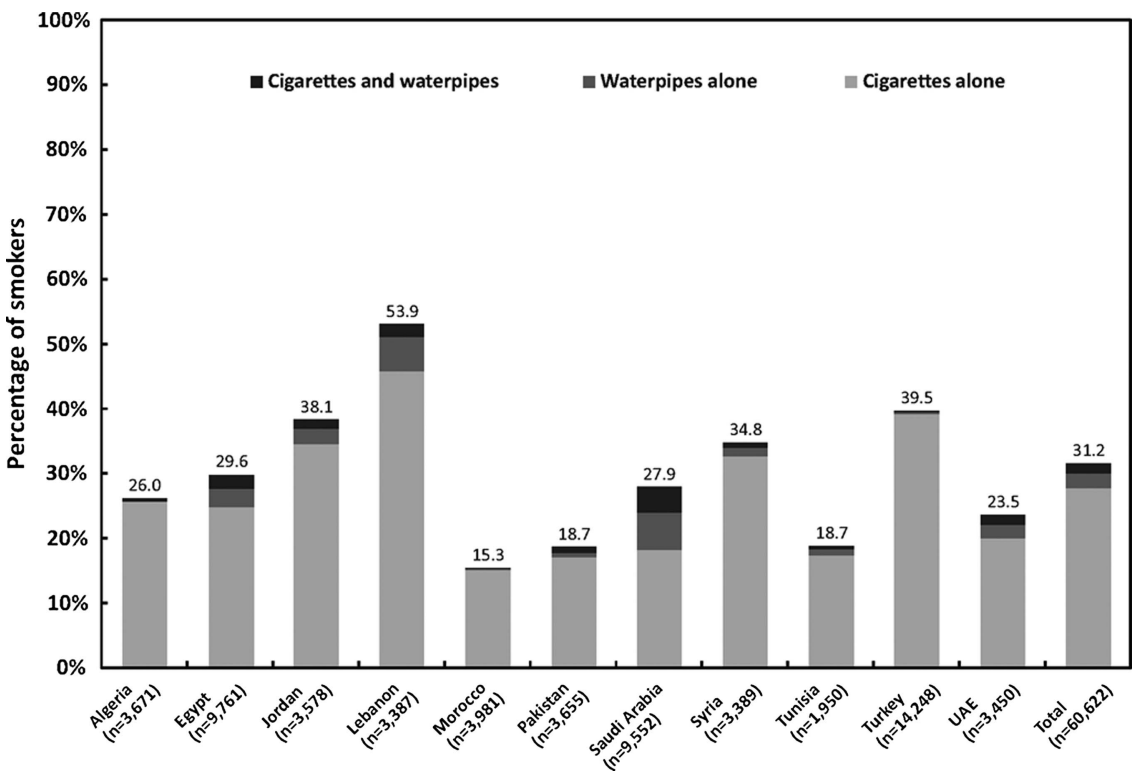


burgeoning epidemic, many countries continue to neglect waterpipe smoking in their tobacco use surveillance and tobacco control policies, or continue to count it under the broad umbrella of 'other tobacco use'. The good news is that waterpipe research during the past decade has provided the critical knowledge needed to deal with the waterpipe epidemic at different levels. As a result, standardised measures that can capture meaningful gradients in waterpipe use for population surveillance are currently available, since a primarily intermittent tobacco use method would not be clearly described under broad terms such as ever or current smoking. ${ }^{65}$ Other basic differences from cigarettes, such as the time spent on waterpipe smoking should also be captured in epidemiological surveillance of the waterpipe, since it has important implications on estimating harmful exposures and future morbidity and mortality. Knowledge accumulated about the harmful and addictive effects of waterpipe smoking moreover, can guide prevention and intervention efforts, while identifying epidemiological patterns of use can guide targeted approach to those at increased risk. In contrast to the expanding knowledge base about the waterpipe, the policy response to the waterpipe epidemic continues to lag behind. As most tobacco control policies and regulations are cigarette-tailored, adapting those policies to the specifics of waterpipe and applying existing ones to it is of major importance. Health warnings, youth access limitation, bans on advertisement and flavouring, clean indoor air laws and tobacco taxation already exist in many societies, and bringing waterpipe venues, products and retailers under these policies can be a major step in advancing waterpipe control in these societies. Other evidence accumulated in the past decade about different aspects of the waterpipe and summarised in this supplement should provide a workable roadmap for waterpipe prevention and control.

\section{What this paper adds}

- In the past decade, waterpipe smoking has become a global epidemic, and is competing with cigarettes in terms of popularity among youth.

- Factors contributing to the global spread of waterpipe include; the introduction of Maassel, the thriving café culture, the rise of the Internet and social media, and the lack of waterpipe-specific regulations and policies.

- Waterpipe smoking seems to cluster among younger age groups, males, the educated and those who smoke cigarettes.

- Despite worrisome trends in waterpipe smoking, we have become better equipped in the past decade to deal with the waterpipe epidemic at different levels, including progress in waterpipe specific surveillance, knowledge about its harmful and addictive properties, groups at most risk, and the need for a specific framework for policy and regulations to limit its spread.

\footnotetext{
Author affiliations

${ }^{1}$ Department of Epidemiology, Florida International University, Miami, Florida, USA

${ }^{2}$ Syrian Center for Tobacco Studies, Aleppo, Syria

${ }^{3}$ Faculty of Medicine and Health Sciences, University of Aden, Aden, Yemen

${ }^{4}$ Department of Epidemiology and Biostatistics, Arnold School of Public Health, University of South Carolina, Columbia, South Carolina, USA

${ }^{5}$ Department of Health Services Policy and Management, Arnold School of Public Health, University of South Carolina, Columbia, South Carolina, USA
}

Contributors WM conceptualised the research idea and took the lead in the writing of the manuscript. ZBT, RB, FI, RJ, RA and RGS contributed to data extraction and helped draft the manuscript. All authors read and approved the final draft.

Funding This work was supported by the National Institute on Drug Abuse grant number R01 DA035160.

\section{Competing interests None.}

Provenance and peer review Commissioned; externally peer reviewed.

Open Access This is an Open Access article distributed in accordance with the Creative Commons Attribution Non Commercial (CC BY-NC 4.0) license, which permits others to distribute, remix, adapt, build upon this work non-commercially, and license their derivative works on different terms, provided the original work is properly cited and the use is non-commercial. See: http://creativecommons.org/ licenses/by-nc/4.0/

\section{REFERENCES}

1 Maziak W, Ward K, Soweid RAA, et al. Tobacco smoking using a waterpipe: a re-emerging strain in a global epidemic. Tob Control 2004;13:327-33.

2 Maziak W. The waterpipe: an emerging global risk for cancer. Cancer Epidemiol 2013;37:1-4

3 Maziak W. The global epidemic of waterpipe smoking. Addict Behav 2011;36:1-5.

4 Maziak W, Ward KD, Eissenberg T. Interventions for waterpipe smoking cessation. Cochrane Database Syst Rev 2007;(4):CD005549. (accessed as up-to-date: 8 Mar 2011).

5 Rastam S, Ward KD, Eissenberg T, et al. Estimating the beginning of the waterpipe epidemic in Syria. BMC Public Health 2004;4:32.

6 Maziak W, Nakkash R, Bahelah R, et al. Tobacco in the Arab world: old and new epidemics amidst policy paralysis. Health Policy Plan 2014;29:784-94.

7 Martinasek MP, McDermott RJ, Martini L. Waterpipe (hookah) tobacco smoking among youth. Curr Probl Pediatr Adolesc Health Care 2011;41:34-57.

8 Maziak W. The waterpipe: time for action. Addiction 2008;103:1763-7.

9 Sutfin EL, Song EY, Reboussin BA, et al. What are young adults smoking in their hookahs? A latent class analysis of substances smoked. Addict Behav 2014;9:1191-6.

10 Jukema JB, Bagnasco DE, Jukema RA. Waterpipe smoking: not necessarily less hazardous than cigarette smoking. Netherlands Heart J 2014;22:91-9.

11 Carroll MV, Chang J, Sidani J, et al. Reigniting tobacco ritual: waterpipe tobacco smoking establishment culture in the United States. Nicotine Tob Res Published Online First: 27 Jun 2014. doi:10.1093/ntr/ntu101. [Epub ahead of print]

12 Afifi R, Khalil J, Fouad F, et al. Social norms and attitudes linked to waterpipe use in the eastern mediterranean region. Soc Sci Med 2013;98:125-34.

13 American Lung Association. Tobacco Policy Trend Alert. An emerging deadly trend: Waterpipe tobacco use. http://www.lungusa2.org/embargo/slati/Trendalert_ Waterpipes.pdf (accessed 5 Jul 2014).

14 Nakkash RT, Khalil J, Afifi RA. The rise in narghile (shisha, hookah) waterpipe tobacco smoking: a qualitative study of perceptions of smokers and non smokers. BMC Public Health 2011;11:315.

15 Jawad M. Legislation enforcement of the waterpipe tobacco industry: a qualitative analysis of the London experience. Nicotine Tob Res 2014;7:1000-8.

16 Sutfin E, McCoy TP, Reboussin BA, et al. Prevalence and correlates of waterpipe tobacco smoking by college students in North Carolina. Drug Alcohol Depend 2011;115:131-36.

17 Salloum RG, Osman A, Maziak W, et al. How popular is waterpipe tobacco smoking? Findings from internet search queries. Tob Control 2014. In press.

18 Primack BA, Rice KR, Shensa A, et al. US hookah tobacco smoking establishments advertised on the internet. Am J Prev Med 2012;42:150-6.

19 Carroll MV, Shensa A, Primack BA. A comparison of cigarette- and hookah-related videos on YouTube. Tob Control 2013;22:319-23.

20 Brockman LN, Pumper MA, Christakis DA, et al. Hookah's new popularity among US college students: a pilot study of the characteristics of hookah smokers and their Facebook displays. BMJ Open 2012;2:e001709.

21 Salloum RG, Nakkash RT, Myers AE, et al. Point-of-sale tobacco advertising in Beirut, Lebanon following a national advertising ban. BMC Public Health 2013;13:534.

22 Jawad M, Millett C. Impact of EU flavoured tobacco ban on waterpipe smoking BMJ 2014;348:g2698.

23 Bahelah R. Waterpipe tobacco labeling and packaging and World Health Organization Framework Convention on Tobacco Control (WHO FCTC): a call for action. Addiction 2014;109:333.

24 Sepetdjian E, Shihadeh A, Saliba NA. Measurement of 16 polycyclic aromatic hydrocarbons in narghile waterpipe tobacco smoke. Food Chem Toxicol 2008:46:1582-90.

25 Knishkowy B, Amitai Y. Water-pipe (narghile) smoking: an emerging health risk behavior. Pediatrics 2005;116:e113-19.

26 Chaloupka FJ, Straif K, Leon ME, et al. Effectiveness of tax and price policies in tobacco control. Tob Control 2011;20:235-8. 
27 Gilmore AB, Tavakoly B, Taylor G, et al. Understanding tobacco industry pricing strategy and whether it undermines tobacco tax policy: the example of the UK cigarette market. Addiction 2013;108:1317-26.

28 How To Make Your Own Shisha. http://www.thehookahlounge.org/how-to-makeyour-own-shisha/ (accessed 5 Jul 2014).

29 Primack BA, Hopkins M, Hallett $C$, et al. US health policy related to hookah tobacco smoking. Am J Public Health 2012;102:e47-51.

30 Nakkash R, Khalil J. Health warning labeling practices on narghile (shisha, hookah) waterpipe tobacco products and related accessories. Tob Control 2010;19:235-9.

31 Akl EA, Gunukula SK, Aleem S, et al. The prevalence of waterpipe tobacco smoking among the general and specific populations: a systematic review. BMC Public Health 2011;11:244.

32 El-Awa F, Warren CW, Jones NR. Changes in tobacco use among 13-15-year-olds between 1999 and 2007: findings from the Eastern Mediterranean Region. East Mediterr Health J 2010;16:266-73.

33 Moh'd Al-Mulla A, Abdou Helmy S, Al-Lawati J, et al. Prevalence of tobacco use among students aged 13-15 years in Health Ministers' Council/Gulf Cooperation Council Member States, 2001-2004. J Sch Health 2008;78:337-43.

34 Warren CW, Jones NR, Eriksen MP, et al. Patterns of global tobacco use in young people and implications for future chronic disease burden in adults. Lancet 2006;367:749-53.

35 Primack BA, Shensa A, Kim KH, et al. Waterpipe smoking among US university students. Nicotine Tob Res 2013;15:29-35.

36 Jawad M, Wilson A, Lee JT, et al. Prevalence and predictors of water pipe and cigarette smoking among secondary school students in London. Nicotine Tob Res 2013;15:2069-75.

37 Barnett TE, Smith T, He Y, et al. Evidence of emerging hookah use among university students: a cross-sectional comparison between hookah and cigarette use. BMC Public Health 2013;13:302.

38 Pärna K, Usin J, Ringmets I. Cigarette and waterpipe smoking among adolescents in Estonia: HBSC survey results, 1994-2006. BMC Public Health 2008;8:392.

39 CDC. Tobacco product use among middle and high school students-United States, 2011 and 2012. Centers for Disease Control and Prevention (CDC). MMWR Morb Mortal Wkly Rep 2013;62:893.

40 Czoli CD, Leatherdale ST, Rynard V. Bidi and Hookah use among Canadian youth: findings from the 2010 Canadian youth smoking survey. Prev Chronic Dis 2013;10:E73.

41 Carroll T, Poder N, Perusco A. Is concern about waterpipe tobacco smoking warranted? Aust N Z J Public Health 2008;32:181-2.

42 CDC. Global Tobacco Surveillance System Data (GTSSData). http://nccd.cdc.gov/ gtssdata/Ancillary/DataReports.aspx?CAID=2 (accessed 28 Jun 2014).

43 Warren CW, Asma S, Lee J, et al. Global tobacco surveillance system. The GTSS Atlas. Atlanta: CDC Foundation, 2009.

44 Warren CW, Lea V, Lee J, et al. Change in tobacco use among 13-15-year-olds between 1999 and 2008: findings from the Global Youth Tobacco Survey. Glob Health Promot 2009;16:38-90.

45 Agaku IT, Filippidis FT, Vardavas Cl, et al. Poly-tobacco use among adults in 44 countries during 2008-2012: Evidence for an integrative and comprehensive approach in tobacco control. Drug Alcohol Depend 2014;139:60-70.

46 McKelvey KL, Wilcox ML, Madhivanan P, et al. Time trends of cigarette and waterpipe smoking among a cohort of school children in Irbid, Jordan, 2008-11. Eur J Public Health 2013;23:862-7.
47 Ward KD, Eissenberg T, Rastam S, et al. The tobacco epidemic in Syria. Tob Control 2006;15(Suppl 1):i24-9.

48 Cheron-Launay M, Baha M, Mautrait C, et al. Identifying addictive behaviors among adolescents: a school-based survey. Arch Pediatr 2011;18:737-44.

49 Maziak W, Eissenberg T, Ward KD. Patterns of waterpipe use and dependence: implications for intervention development. Pharmacol Biochem Behav 2005;80:173-9.

50 Smith-Simone S, Maziak W, Ward KD, et al. Waterpipe tobacco smoking: knowledge, attitudes, beliefs, and behavior in two US samples. Nicotine Tob Res 2008;10:393-8.

51 Ward KD, Eissenberg T, Gray JN, et al. Characteristics of US waterpipe users: a preliminary report. Nicotine Tob Res 2007;9:1339-46.

52 Jawad M, Jawad S, Mehdi A, et al. A qualitative analysis among regular waterpipe tobacco smokers in London universities. Int J Tuberc Lung Dis 2013;17: 1364-9.

53 Ward KD, Hammal F, VanderWeg MW, et al. Are waterpipe users interested in quitting? Nicotine Tob Res 2005;7:149-56.

54 Jawad M, McEwen A, McNeill A, et al. To what extent should waterpipe tobacco smoking become a public health priority? Addiction 2013;108:1873-84.

55 Tworek C, Schauer GL, Wu CC, et al. Youth tobacco cessation: quitting intentions and past-year quit attempts. Am J Prev Med. 2014;47(2 Suppl 1):S15-27.

56 Asfar T, Ward KD, Eissenberg T, et al. Comparison of patterns of use, beliefs, and attitudes related to waterpipe between beginning and established smokers. BMC Public Health 2005;5:19.

57 Khattab A, Javaid A, Iraqi G, et al. Smoking habits in the Middle East and North Africa: results of the BREATHE study. Respir Med 2012;106(Suppl 2): S16-24.

58 US Department of Health and Human Services. Preventing tobacco use among youth and young adults: a report of the surgeon general. Atlanta, GA: US Department of Health and Human Services, Centers for Disease Control and Prevention, National Center for Chronic Disease Prevention and Health Promotion, Office on Smoking and Health, 2012.

59 Salameh $\mathrm{P}$, Salamé J, Waked $\mathrm{M}$, et al. Waterpipe dependence in university students and effect of normative beliefs: a cross-sectional study. BMJ Open 2014;4: e004378.

60 Palamar JJ, Zhou S, Sherman S, et al. Hookah use among US high school seniors. Pediatrics 2014;134:227-34

61 Grant A, Morrison R, Dockrell MJ. Prevalence of Waterpipe (Shisha, Narghille, Hookah) Use Among Adults in Great Britain and Factors Associated with Waterpipe Use: Data From Cross-sectional Online Surveys in 2012 and 2013. Nicotine Tob Res 2014;16:931-8

62 Rice VH, Weglicki LS, Templin T, et al. Predictors of Arab American adolescent tobacco use. Merrill Plalmer Q 2006;52:327-42.

63 Mzayek F, Khader Y, Eissenberg T, et al. Patterns of water-pipe and cigarette smoking initiation in schoolchildren: Irbid longitudinal smoking study. Nicotine Tob Res 2012;14:448-54.

64 Maziak W. Commentary: the waterpipe - a global epidemic or a passing fad. Int J Epidemiol 2010;39:857-59.

65 Maziak W, Ward KD, Afifi Soweid RA, et al. Standardizing questionnaire items for the assessment of waterpipe tobacco use in epidemiological studies. Public Health 2005;119:400-4. 